\title{
EFFECT OF BULK DENSITY VARIATION ON THE COMPRESSION STRENGTH OF CLAY-SODIUM SILICATE-BONDED MOULDING SAND
}

\author{
S. A. Ibitoye \\ Department of Materials Science and Engineering \\ Obafemi Awolowo University, Ile-Ife \\ Osun State, Nigeria
}

\begin{abstract}
This paper reports a study conducted to assess the influence of variation of bulk density on compression strength of clay-bonded sand. Five sand mixes containing silica sand, sodium silicate gel (1 wt. \% to 5 wt. \%), potters' clay (2 wt. \%), and about 5 wt. \% water were produced. Each mix was divided into three portions to which wood flour (2 wt. \%) or charcoal (2 wt. \%) or their mixture (1 wt \% each). was added to first, second and third portion respectively. Each portion was thoroughly mixed and AFS cylindrical specimens prepared. Thereafter, bulk densities and compression strength of the prepared samples were measured. It was noted that when wood flour, charcoal or their mixture is added, the characteristics of compression strength of clay-bonded sand assume a parabolic form as the bulk density increases. It was inferred that two factors, namely, the number of sand-grain-to-sand-grain contact and the number of pores in the clay-silica gel formed round the surface of sand grains, produce two opposing influences on the compression strength. The compression strength value attains a maximum when these influences are equalized.
\end{abstract}

Keywords: bulk density, clay, compression strength, metal casting, moulding sand, porosity

\section{INTRODUCTION}

Sand remains the principal and most flexible moulding material suitable for both ferrous and non-ferrous castings. For sand to serve this purpose, it has to possess certain properties vital for moulding purposes. These properties include adequate hardness, permeability, strength, compatibility, mouldability, shatter index, plasticity, refractiveness, fineness, collapsibility, bulk density among others. For given sand, the values of these properties are influenced by the constituent components and method of preparation (Jain, 1979; Rao, 1998).

One aspect of sand mould preparation that can influence some of these properties is degree of ramming or compaction of the sand. The degree of ramming significantly affects the properties dependent on packing, which is indicated by the bulk density. These properties are hardness, permeability and strength (Jain, 1979; Heine et al., 1967). 
The value of mould hardness depends among others, on the degree of ramming (Rao, 1998; Beeley, 2001). Soft ramming leads to low mould hardness which is one of the causes of 'drop', a situation whereby the cope surface cracks and breaks. The pieces of sand so broken are eventually enveloped by the molten metal and later constitute sand inclusions in the solidified castings (Rao, 1998; Khanna and Lal, 1996). Hard ramming on the other hand leads to excessive hardness, which prevents the compacted sand from collapsing to relieve stress on the shrinking metal, and so can lead ultimately to hot tears in casting. Bulk density, which is an indication of degree of ramming and consequently the hardness, is therefore significant for the production of sound and defect-free castings.

Strength is also influenced by bulk density. Moderate compaction results in a bulk density that ensures optimum strength. Soft ramming leads to low green strength which encourages sand erosion, and the creation of inclusions, when the metal is poured. Insufficient ramming can also cause swell, which is an enlargement of mould cavity by metal pressure resulting in localized or an overall enlargement of the casting (Rao, 1998).

Permeability, another packing property, decreases as bulk density increases [(Heine et al., 1967; Beeley, 2001). Inadequate permeability may cause gas entrapment within the mould and thus gas porosity in the casting.

The achievement of the correct bulk density is a step towards the preparation of moulding sand of adequate strength, hardness and permeability. Deficiencies in any of these properties can result in production of defected castings, which eventually lowers daily productivity in the foundry. In order to improve the efficiency and productivity of foundry, it therefore becomes imperative to investigate the effect of bulk density on the compression strength of clay-bonded sand. Although the changes in green strength of moulding sand with bulk density has been reported
(Beeley, 2001) no report however has been made on the response of compression strength of sand to changes in bulk density when a mixture of sodium silicate and potters' clay is used as binder. This is the object of this investigation.

\section{EXPERIMENTAL PROCEDURE}

Dried potters' clay (obtained from Ipetumodu clay deposit), silica sand (from Osun River Bank), wood flour and powdered charcoal were separately ground and sieved to a fineness of $300 \mathrm{mi}-$ crons. The results of the trial run indicated that within the range of $1 \%-5 \%$ potters' clay content, other properties of the moulding sand are not impaired. For this reason, five different mixes of silica and potters' clay containing $1 \%-5 \%$ potters' clay respectively were prepared. Each of the mixes was divided into three groups. To the first group of each mix, $2 \mathrm{wt} \%$ prepared wood flour was added, 2 wt \% prepared charcoal to the second group and a mixture containing 1 wt \% each of both the wood flour and charcoal was added to the third group. The choice of these values of wood flour and charcoal was based on the results of the previous work, which showed that for potters' clay-bonded moulding sand, the moulding properties are optimum when the content of these additives are in the range of $2.4 \mathrm{wt} . \%$ to $8.0 \mathrm{wt}$. $\%$ (Ibitoye and Afonja, 1997). Each of the three groups was then sub-divided into five portions and thereafter, 2 wt. $\%, 4$ wt. $\%, 6$ wt. $\%, 8$ wt. $\%$ and 10 wt. $\%$ sodium silicate gel (water glass), with density of $1.48 \mathrm{~g} / \mathrm{cm}^{3}$, was added to the first, second, third, fourth, and fifth portion respectively. The results of the trial run showed that reasonable values of the properties under investigation are obtainable when the sodium silicate gel content is in the range of approximately $1 \mathrm{wt} . \%$ to $10 \mathrm{wt}$. $\%$. Three percent water was added to each of the mixes based on the result of the previous work which showed that the optimum properties of potters' clay-bonded moulding sand is obtained when the water content is in the range of 0.5 wt. $\%$ to 5.0 wt. \% (Ibitoye and Afonja, 1996). The constituents were thoroughly mixed in accordance with AFS Standard procedure (AFS 
Sand Handbook, 1963). A sample of $150 \mathrm{~g}$ of each of the prepared mixes was measured into a standard cylindrical specimen tube and compacted using a standard rammer. The bulk densities of the rammed samples were determined (AFS Sand Handbook, 1963). Thereafter, the compression strength of each mix was measured using a Universal Strength Tester having passed a stream of carbon dioxide through the specimen for about 15 seconds.

\section{RESULTS AND DISCUSSION}

The changes in compression strength with variation in the bulk density when wood flour is used as an additive for different sodium silicate $\left(\mathrm{Na}_{2} \mathrm{SiO}_{3}\right)$ contents are presented in Figure 1 . The compression strength of the sand mixes gives parabolic characteristics as the bulk density increases (Figure 1). For the mix containing $2 \% \mathrm{Na}_{2} \mathrm{SiO}_{3}$, compression strength of $43 \mathrm{kN} / \mathrm{m}^{2}$ is obtained at a bulk density of $1.53 \mathrm{~g} / \mathrm{cm}^{3}$. As the bulk density increases to $1.54 \mathrm{~g} / \mathrm{cm}^{3}$, the compression strength rapidly attains a maximum value of $110 \mathrm{kN} / \mathrm{m}^{2}$ and thereafter, starts to drop rapidly to $61.5 \mathrm{kN} / \mathrm{m}^{2}$ as the bulk density rises to $1.55 \mathrm{~g} / \mathrm{cm}^{3}$. Similar characteristics are exhibited by other four mixes containing $4 \%$ to $10 \%$ $\mathrm{Na}_{2} \mathrm{SiO}_{3}$ respectively.

The changes in compression strength with bulk density when charcoal is used as an additive are presented in Figure 2. As observed with mixes containing wood flour, the compression strength increases to a peak value for a given $\mathrm{Na}_{2} \mathrm{SiO}_{3}$ content and thereafter falls. Similar observations are made when the mixture of both additives is used (Figure 3).

The peak compression strength values obtained at various $\mathrm{Na}_{2} \mathrm{SiO}_{3}$ contents when wood flour, charcoal and their mixture are used are extracted from Figure 1, Figure 2 and Figure 3 respectively and they are presented in Table 1 .

Some properties of moulding sand such as hardness, green compression strength and permeability are directly related to its bulk density (Beeley, 2001). Bulk density of moulding sand progressively increases as the amount of work done in compacting it increases (Heine et al., 1967).

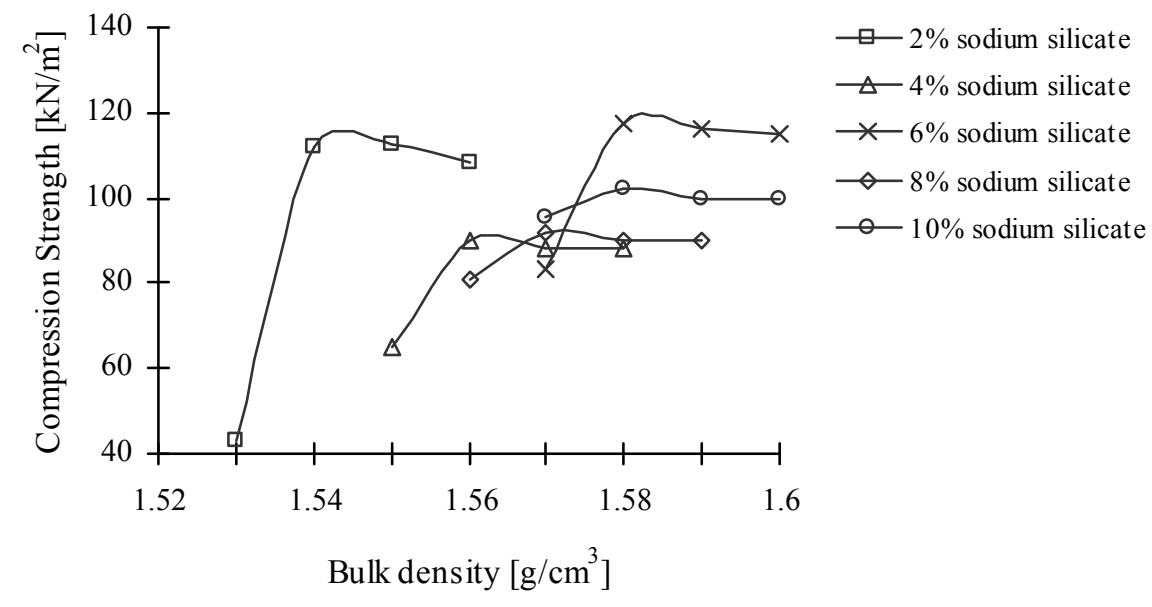

Figure 1: The Plot of Compression Strength vers us Bulk Density Using $2 \%$ Wood Flour as an Additive 


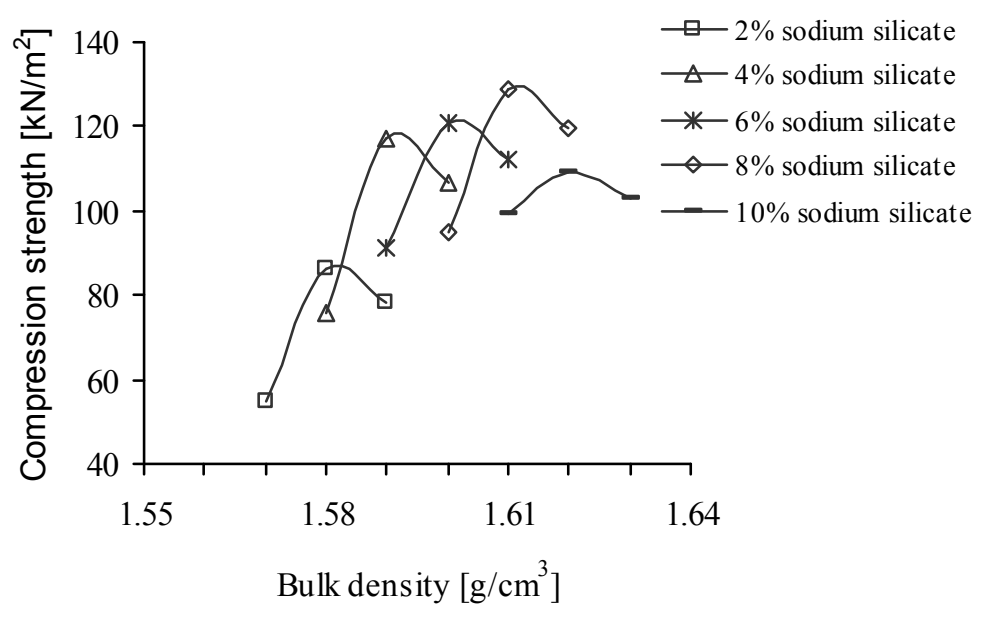

Figure 2: The Plot of Compression Strength versus Bulk Density Using 2\% Charcoal as an Additive

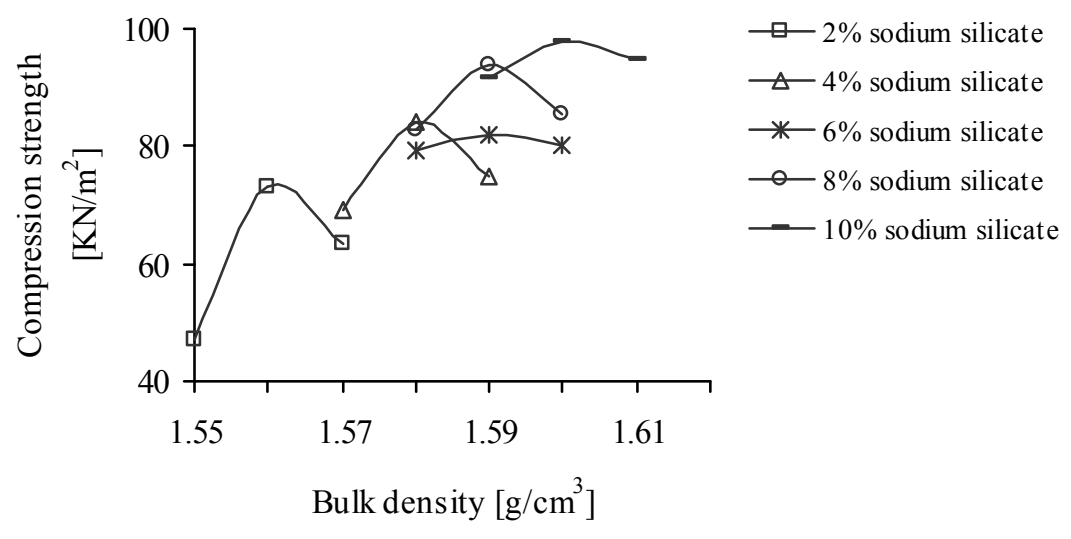

\section{Figure 3: Compression Strength versus Bulk Density Using Mixture of $1 \%$ Each of Wood Flour and Charcoal}

The changes in the compression strength with an increasing bulk density of sand mixes containing wood flour can be explained on the basis of the $\mathrm{Na}_{2} \mathrm{SiO}_{3}$ and clay interaction in the sand mix. In clay bonded sand, the clay forms lens shaped masses at the point of contacts of grains. Sodium silicate on the other hand, forms a thin film around the grains when mixed with silica sand. Together with the available clay in the mix, the film of sodium silicate-clay coating is formed round available silica particles at points of contact of the grains (Heine et al., 1967; Khanna and Lal,

144 Journal of Science and Technology, Vol. 27, No. 3, December 2007 
Table 1: Maximum compressive strength at various sodium silicate contents for different additives

\begin{tabular}{cccc}
\hline $\begin{array}{c}\mathrm{Na}_{2} \mathrm{SiO}_{3} \\
\text { Content } \\
{[\text { wt.\%] }}\end{array}$ & Wood flour (WF) & Charcoal (C) & WF + C \\
\hline 2 & 112.3 & 86.0 & 73.0 \\
4 & 90.0 & 117.0 & 84.0 \\
6 & 117.0 & 121.0 & 82.0 \\
8 & 95.2 & 129.0 & 94.0 \\
10 & 100.0 & 109.0 & 98.0 \\
\hline
\end{tabular}

1996; Beeley, 2001). With the aid of available water in the mix, the clay-sodium silicate coating develops plasticity, which eventually produces a bond between neighbouring particles at the points of contact. This gives rise to increase in net attractive forces generated between hydrated clay-sodium silicate particles and between these and the quartz surfaces (Khanna and Lal, 1996; Beeley, 2001). Consequently, proportional increase in strength is developed in the bond material between the sand grains.

The strength of the mould material is a function of the number and area of these contacts (Beeley, 2001). As bulk density increases in a clayunsaturated mix, the number and the area of grain-to-grain contact per unit volume also increase (Beeley, 2001; Ibitoye and Afonja, 2001; Ibitoye et al., 2002). This perhaps explains the observed increase in the compression strength with increasing bulk density for mixes containing wood flour (Figure 1).

It is noted that for a prepared mix of a given sodium silicate content, as bulk density increases, the compression strength increases up to a maximum and thereafter, starts to decrease before limiting bulk density is attained (Figure 1). This is a slight modification to previously reported findings that the compression strength keeps increasing as the bulk density increases until no further increase in bulk density is possible (Heine et al., 1967; Beeley, 2001).
The possible reason for this unusual behaviour may be associated with the clay-sodium silicate coating round the silica particles. Sodium silicate in the presence of carbon dioxide gives rise to formation of sodium silicate gel, which is porous, and with large surface area (Hicks, 1971; Liptrot, 1975). This large surface area in the presence of water-activated clay favours formation of strong interparticle bond and consequently, increasing compression strength as the bulk density increases. Porosity on the other hand, reduces the area and the number of sand-grain-to-sand-grain contacts of which the strength is a function (Beeley, 2001). This means that there are two opposing factors at work as the bulk density increases. This may imply that, initially when the bulk density is low, the influence of the first factor on the compression strength is very high. And so, as the bulk density increases, the increase in the compression strength due to the first factor exceeds the decrease brought about by second factor (increased porosity). This may account for the observed initial continuous increase in the compression strength up to maximum bulk density for instance, of about $1.54 \mathrm{~g} / \mathrm{cm}^{3}$ for the mix containing $2 \%$ wood flour (Figure 1). At this maximum compression strength, the influence due to the two factors on the compression strength may be said to equalize. However, while the bulk density increases, the sand aggregate packed into a unit volume also increases so also the quantity of the clay-silica gel coatings formed 
around these particles within a unit volume. That is, the influence of the second factor keeps increasing. Consequently, further increase in the bulk density beyond $1.54 \mathrm{~g} / \mathrm{cm}^{3}$ produces a decrease in the compression strength, which may be attributed to the much greater influence of the second factor on the compression strength. The same explanation holds for all other mixes containing wood flour (Figure1) and for results obtained when charcoal or mixture of wood flour and charcoal is used (Figures 2 - 3).

The peak values of compression strength for mixes of different $\mathrm{Na}_{2} \mathrm{SiO}_{3}$ content for a given additive extracted from Figures $1-3$ are not the same and are presented in Table 1 . These peak values form data points scatter displayed in Figure 4 . In order to obtain the optimum compression strength for mixes of different $\mathrm{Na}_{2} \mathrm{SiO}_{3}$ content for a given additive, a plot of a curve of best fit for the data is required. Most reliable best fit curve for data points scatter is obtained when Rsquared value of regression (R) analysis of such data is at or near 1 .

With the use of EXCEL software, the data points scatter for mixes containing wood flour are best described by Equation (1) which produces linear curve with $\mathrm{R}^{2}=0.9548$ (Figure 4 ). $y=1.4 x+98.22$

where $\mathrm{y}$ is the maximum compression strength and $\mathrm{x}$ is the $\mathrm{Na}_{2} \mathrm{SiO}_{3}$ content.

The maximum compression strength obtainable when wood flour is used as an additive is therefore best described by a linear characteristic with optimum compression strength of $100 \mathrm{kN} / \mathrm{m}^{2}$ to $110 \mathrm{kN} / \mathrm{m}^{2}$ as $\mathrm{Na}_{2} \mathrm{SiO}_{3}$ content increases from 2wt $\%$ to 10 -wt $\%$ respectively (Figure 4 ).

Similarly, regression analysis of data of maximum compression strength of mixes containing charcoal (Table 1) are best described by parabolic curve described by equation (2) with $\mathrm{R}^{2}=1$ (Figure 4).

$$
y=-6.85 x^{2}+46.864 x+45.982
$$

This gives maximum compression strength that range from $86 \mathrm{kN} / \mathrm{m}^{2}$ to $109 \mathrm{kN} / \mathrm{m}^{2}$ with $\mathrm{Na}_{2} \mathrm{SiO}_{3}$ content ranging from $2 \mathrm{wt} \%$ to $10 \mathrm{wt} \%$ respectively. The compression strength in this case optimises at about $127 \mathrm{kN} / \mathrm{m}^{2}$ when the $\mathrm{Na}_{2} \mathrm{SiO}_{3}$ content is $6.8 \mathrm{wt} \% \%$ (Figure 4 ).

Employing the mixture of both wood flour and charcoal as an additive, the characteristic of the

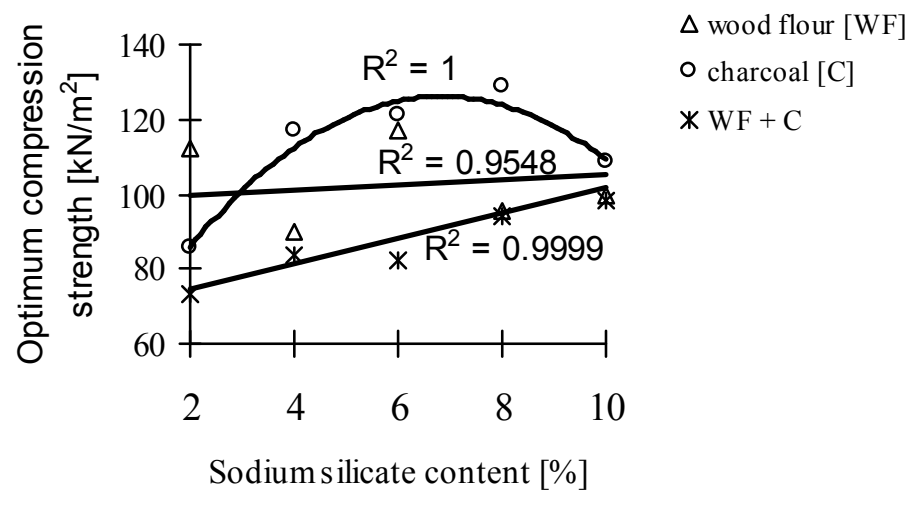

Fig. 4: The Optimum Compres sion Strength Profile with Sodium Silicate Content for different Additives

146 Journal of Science and Technology, Vol. 27, No. 3, December 2007 
maximum obtainable compression strength shows a gradual linear increase described by equation (3) with $\mathrm{R}^{2}=0.9999$ which is very close to 1 .

$$
y=6.9 x+67.52
$$

This produces optimum compression strength ranging from about $75 \mathrm{kN} / \mathrm{m}^{2}$ to $100 \mathrm{kN} / \mathrm{m}^{2}$ as the $\mathrm{Na}_{2} \mathrm{SiO}_{3}$ content rises from $2 \mathrm{wt} \%$ to $10 \mathrm{wt}$ $\%$ (Figure 4).

Bulk density of clay bonded sand is influenced largely by the type and quantity of binders, additives used (Ibitoye et al, 2002) and the level of compaction (Heine et al, 1967). Bulk density of clay-bonded moulding sand containing either 2 wt.\% wood flour, 2 wt. $\%$ charcoal, or 1 wt. $\%$ each of the two additives is noted to increase linearly with an increase in either $\mathrm{Na}_{2} \mathrm{SiO}_{3}$ or clay content (Ibitoye et al., 2002). Every one percent increase in the $\mathrm{Na}_{2} \mathrm{SiO}_{3}$ and clay content results in approximately $0.07 \mathrm{~g} / \mathrm{cm}^{3}$ and $0.01 \mathrm{wt}$. $\%$ rise respectively in the bulk density of sand mix containing 2 wt.\% wood flour. These values change for different additives (Ibitoye et al., 2002). Some organic additives such as wood flour, charcoal cereal, dextrin and their mixture slightly decrease the bulk density when added to clay bounded moulding sand. They however impart some special properties such as collapsibility, mouldability and permeability to moulding and core sands (Heine et al., 1967; Khanna and Lal, 1996; Beeley, 2001). Therefore, the bulk densities recorded are a function of $\mathrm{Na}_{2} \mathrm{SiO}_{3}$ and clay contents, the level of compaction of the mixes and to a limited extent, the additives used.

As earlier mentioned, the density is directly related to compression strength. The addition of wood flour, charcoal and their mixture to potters' clay-bounded moulding sand have been found to have weakening effect on the compression and shear strength (Ibitoye and Afonja, 1996). This is found noticeable when they are present in an amount ranging from 2.4 wt. \% -
$8.0 \mathrm{wt} \%$ by which the overall moulding properties of the sand mix is optimum. However, below this range down to $1.8 \mathrm{wt} . \%$, the influence of each of these additives on the compression strength is not pronounced but adequate enough to achieve its purpose without significant influence on the compression strength (Ibitoye and Afonja, 1996). The observed increase and decrease in the compression strength can therefore be attributed mainly to not only the compaction but also the influence of the added clay and $\mathrm{Na}_{2} \mathrm{SiO}_{3}$ binders.

\section{CONCLUSION}

The characteristics of compression strength of clay-sodium silicate bonded sand assume parabolic form as the bulk density increases for sand mixes containing wood flour, charcoal or their mixture as an additive. Increase in the number of sand-grain-to-sand-grain contact and the number of porosities in the formed clay-silica gel round the surface of sand grains are two factors identified to have an opposing influence on the compression strength. The compression strength increases with increasing bulk density when the first factor is predominant while it decreases when the second is predominant. The compression strength attains a peak value when the influence of the two factors equalizes. The 'peak' phenomena observed due to the porosity component in this study is additional information to the previously reported findings that the compression strength keeps increasing as the bulk density increases. The optimum compression strength obtainable is highest when charcoal alone is used as an additive while it is lowest when the mixture of both charcoal and wood flour is used. The bulk density and consequently the compression strength are influenced mainly by the $\mathrm{Na}_{2} \mathrm{SiO}_{3}$, the clay and to a very limited extent, the additives used.

\section{REFERENCES}

Jain, P. L. (1979). Principles of Foundry Technology, McGraw-Hill, New Delhi: 49-74. 
Rao, P. N. (1998). Manufacturing Technology Foundry, Forming and Welding, Tata McGraw-Hill, New Delhi: 64-65.

Heine, R. W., Loper, Jr C. R. and Rosenthal, P. C. (1967). Principles of Metal Casting, $2^{\text {nd }}$ ed., McGraw Hill, New York: 54-54

Beeley, P. (2001). Foundry Technology, Butterworth-Heinemann, Oxford: 202-213

Khanna, O. P. and Lal, M. (1996). A Text Book of Foundry Technology, Dhanpat Rai, New Delhi: 486-491.

Ibitoye, S. A. and Afonja, A. A. (1997). Adaptation of Ipetumodu Potters' Clay to Foundry Use -II - Development of Potters' ClayBound Synthetic Moulding Sand, Ife Journal of Technology (IJT), 7(1): 39-45.

Ibitoye, S. A. and Afonja, A. A. (1996). Determination of Optimum Water Content of Potters' Clay-Bonded Moulding Sand, Ife Journal of Technology (IJT), 6(1): 25-30.
AFS Sand Handbook (1963). American Foundrymen Soc., 7th ed., Des Plaines, Illinois: 1245 .

Ibitoye, S. A. and Afonja, A. A. (2001). Moulding properties of as-mined and silicaenriched potters' clay; Journal of Construction and Materials Technology, 1 (2): 3-9.

Ibitoye, S. A., Amuda, O. H. and Oparinde, G. M. (2002). Effect of the addition of sodium silicate on the bulk density of clay-bonded moulding sand, Nigerian Journal of Industrial and Systems Studies (NJISS), 1(2): 2026.

Hicks, J. (1971). Comprehensive Chemistry, $2^{\text {nd }}$ ed., MacMillan, London: 420-421.

Liptrot, G. F. (1975). Modern Inorganic Chemistry, $2^{\text {nd }}$ ed., Mills \& Boon, Hampshire: 229234. 